\title{
Validating an empiric sulfadiazine-trimethoprim dosage regimen for treatment of Escherichia coli and Staphylococcus delphini infections in mink (Neovison vison)
}

\author{
Amir Atabak Ronaghinia, ${ }^{1,2}$ (D) | Nanett Kvist Nikolaisen ${ }^{2,3}$ | Stine Green Hansen ${ }^{2}$ | \\ Helle Harding Poulsen ${ }^{4}$ | Henrik Lauritz Frandsen ${ }^{5}$ | Tina Struve ${ }^{2}$ | \\ Pierre-Louis Toutain $^{6,7}$ (1) | Peter Damborg ${ }^{1}$
}

${ }^{1}$ Department of Veterinary and Animal Sciences, Faculty of Health and Medical Sciences, University of Copenhagen, Frederiksberg, Denmark

${ }^{2}$ Kopenhagen Diagnostics, Department of Health and Diagnostics, Kopenhagen Fur a.m.b.a, Glostrup, Denmark

${ }^{3}$ National Food Institute, Research Group for Microbiology and Hygiene, Technical University of Denmark, Kongens Lyngby, Denmark

${ }^{4}$ Department of Veterinary Clinical Sciences, Faculty of Health and Medical Sciences, University of Copenhagen, Frederiksberg, Denmark

${ }^{5}$ National Food Institute, Technical University of Denmark, Kongens Lyngby, Denmark

${ }^{6}$ Royal Veterinary College, University of London, London, UK

${ }^{7}$ INTHERES, Université de Toulouse, INRA, ENVT, Toulouse, France

\section{Correspondence}

Amir Atabak Ronaghinia, Department of Veterinary and Animal Sciences, Faculty of Health and Medical Sciences, University of Copenhagen, Stigbøjlen 4, 1870

Frederiksberg C, Denmark.

Email:amiratabak@sund.ku.dk

Funding information

Innovationsfonden, Grant/Award Number: 5189-00060B ; Danish fur breeder association

\begin{abstract}
Antimicrobial agents are used extensively off-label in mink, as almost no agents are registered for this animal species. Pharmacokinetic (PK) and pharmacodynamic (PD) data are required to determine antimicrobial dosages specifically targeting mink bacterial pathogens. The aims of this study were to assess, in a PKPD framework, the empirical dosage regimen for a combination of trimethoprim (TMP) and sulfadiazine (SDZ) in mink, and secondarily to produce data for future setting of clinical breakpoints. TMP and SDZ PK parameters were obtained experimentally in 22 minks following IV or oral administration of TMP/SDZ $(30 \mathrm{mg} / \mathrm{kg}$, i.e. $5 \mathrm{mg} / \mathrm{kg} \mathrm{TMP}$ and $25 \mathrm{mg} / \mathrm{kg} \mathrm{SDZ}$ ). fAUC/MIC with a target value of $24 \mathrm{hr}$ was selected as the PKPD index predictive of TMP/SDZ efficacy. Using a modeling approach, PKPD cutoffs for TMP and SDZ were determined as 0.062 and $16 \mathrm{mg} / \mathrm{L}$, respectively. By incorporating an anticipated potentiation effect of SDZ on TMP against Escherichia coli and Staphylococcus delphini, the PKPD cutoff of TMP was revised to $0.312 \mathrm{mg} / \mathrm{L}$, which is above the tentative epidemiological cutoffs (TECOFF) for these species. The current empirical TMP/SDZ dosage regimen $(30 \mathrm{mg} / \mathrm{kg}$, PO, once daily) therefore appears adequate for treatment of wild-type E. coli and S. delphini infections in mink.
\end{abstract}

\section{KEYWORDS}

Escherichia coli, mink, Neovison vison, Staphylococcus delphini, sulfadiazine, trimethoprim

\section{1 | INTRODUCTION}

Potentiated sulfonamides are combinations of a sulfonamide and a diaminopyrimidine (typically trimethoprim (TMP)), which exhibit synergistic bactericidal effects by interfering at two different stages in the process of bacterial folic acid biosynthesis. Sulfonamides are analogous to para-aminobenzoic acid with competitive affinity to dihydropteroate synthase, and diaminopyrimidines can bind to dihydrofolate reductase, thereby hindering the synthesis of tetrahydrofolic acid (Mengelers, Hougee, Janssen, \& Van Miert, 1997; Van 
Miert, 1994). It has been shown in vitro that TMP and sulfonamides act synergistically against several bacterial species and that synergism may be obtained in humans when these drugs are administered in a 1:5 ratio. (Bushby, 1973; Kielhofner, 1990). Although the same ratio is applied in veterinary preparations, it is often unknown whether or not a synergistic effect is obtained in animals (Van Miert, 1994).

Pharmaceutical preparations containing the combination of sulfadiazine (SDZ) and TMP (SXD) are frequently used in mink farms against infections that have a major impact on animal health and consequently on the production of mink fur. Among the most common bacterial pathogens in mink are Escherichia coli (causing, e.g. enteritis and septicemia), Staphylococcus delphini (causing, e.g. wound infections and dermatitis) and Pseudomonas aeruginosa (causing, e.g. hemorrhagic pneumonia; Nikolaisen et al., 2017; Pedersen, Hammer, Sørensen, \& Heuer, 2009). SXD dosage regimens currently used in mink derive from other animals, as there are no mink-specific SXD products on the market and no pharmacokinetic (PK) and pharmacodynamic (PD) data available to support the development of a mink-specific dosage regimen. The consequences of such off-labe antimicrobial use in mink are unknown, but may include treatment failure and emergence of antimicrobial resistance (Schwarz, Cavaco, Shen, \& Aarestrup, 2018).

PKPD modeling and simulation have been investigated extensively as an alternative approach for conventional antimicrobial dose titration studies (Lees \& Aliabadi, 2004; Toutain, Del Castillo, \& Bousquet-Mélou, 2002). Using this approach, drug disposition $(\mathrm{PK})$ is explored experimentally in the target animal species. PK data are then linked to in vitro PD data (e.g. MIC distributions) through a PKPD index, which is the quantitative relationship between a PK parameter and a microbiological parameter (MIC), that is predictive of clinical efficacy (Mouton et al., 2018; Toutain et al., 2017). There are two PKPD indices predicting antimicrobial efficacy in veterinary medicine, namely duration of drug plasma concentration above the MIC ( $F$ T > MIC) and area under the serum concentration-time curve divided by the MIC (fAUC/MIC) (Toutain et al., 2017). The latter has been proposed as the most applicable PKPD index for SXD (Asín-Prieto, Rodríguez-Gascón, \& Isla, 2015; Cheng et al., 2009). Once a PKPD index has been defined for a drug, the PKPD target is determined, which is the magnitude of the PK parameter related to the MIC, that is associated with cure (e.g. $A U C / M I C=24$ hr). Mathematical modeling can then be used to convert experimental PK data to population PK data, and results may be used to determine the PKPD cutoff, which is the highest MIC value at which a given percentage (typically 90\%) of a target population reaches the desired PKPD target. Once the PKPD cutoff has been determined, the antimicrobial dosage can be optimized taking into account the MIC distribution for target pathogens (Muller, Theuretzbacher, \& Mouton, 2015). Apart from setting a dosage regimen, the PKPD cutoff can be used together with clinical outcome data and epidemiological cutoffs (ECOFFs) for establishing clinical breakpoints (CBP) (Toutain et al., 2017). CBPs are used to identify microorganisms as clinically susceptible
(S), intermediate (I), or resistant (R) depending on the outcome of antimicrobial susceptibility tests in standard test systems (Mouton et al., 2012).

The objectives of this study were to (a) establish PK data for SDZ and TMP in mink after intravenous (IV) and oral administration of SXD, (b) investigate the effect of blood sampling site (vein versus nail) and feeding status (fed versus fasted) on PK parameters in mink, (c) evaluate the current empirical dosage regimen of SXD for mink bacterial infections after oral administration in feed, and (d) to provide data for development of CBPs for target pathogens in mink.

\section{2 | MATERIALS AND METHODS}

\section{1 | Ethical approval}

This study was approved by the Danish Animal Experiment Inspectorate (permit no. 2017-15-0201-01291) and by the Danish Medicines Agency (permit no. 2017083950).

\subsection{Animal experiments}

Three experiments with a total of 22 minks were conducted: In the first two studies, we investigated the disposition of SDZ and TMP after IV administration, and the third study was an evaluation of PK parameters of these drugs after oral administration. The animals were male brown minks (Neovison vison) purchased from a commercial mink farm. In accordance with the Danish order BEK nr 856 of $27.06 .2013 \S 1$, minks were housed individually in cages with an attached nest, a water bottle, a plastic shelf, and a plastic tube for enrichment. Upon purchase, all animals were acclimatized in their new environment for seven days prior to each experiment. The minks were provided with ad libitum water and were fed 250$300 \mathrm{~g}$ of commercial feed per day. In the third study, on the day of the experiment, the amount of antimicrobial-supplemented feed was adjusted precisely to the weight of each animal, as described below.

\subsection{1 | First in vivo study: PK of SDZ and TMP over $24 \mathrm{hr}$ after SXD IV injection}

The PK parameters of SDZ and TMP after IV administration of SXD were investigated in the first study. Ten minks were divided randomly into a fed $(n=5)$ and a nonfed $(n=5)$ group in order to assess the impact of feeding state on PK parameters. The fed group was fasted for two hours before anesthesia (see section 2.4) to prevent complications. The nonfed group was fasted for $24 \mathrm{hr}$ before anesthesia. Upon anesthesia, each animal was subjected to cephalic IV administration of SXD (Tribrissen ${ }^{\circledR}$ Vet 48\%, Intervet International, Boxmeer, the Netherlands) at the dose of $30 \mathrm{mg} / \mathrm{kg}$ of body weight (i.e. $5 \mathrm{mg} / \mathrm{kg}$ TMP and $25 \mathrm{mg} / \mathrm{kg}$ SDZ). Paired cephalic and nail blood 
samples were collected under anesthesia immediately before and at nine sampling points after antimicrobial administration $(5,15,30,60$, $120 \mathrm{~min}$ and $6,10,15$, and $24 \mathrm{hr}$.

\subsection{2 | Second in vivo study: PK of SDZ over $72 \mathrm{hr}$ after SXD IV injection}

An additional PK study over $72 \mathrm{hr}$ had to be done, as the serum concentration of SDZ exceeded the lower limit of quantification (LLOQ = $128 \mathrm{ng} / \mathrm{mL}$; section 2.6) after $24 \mathrm{hr}$ in the first animal experiment. The study was conducted as described above, except for the following differences: (a) Six minks were included and they were all fasted for two hours before anesthesia, and (b) blood samples were taken only by nail clipping before antibiotic administration and afterward at the time points $12,24,48$, and $72 \mathrm{hr}$.

\subsubsection{Third in vivo study: PK of SDZ and TMP after SXD oral administration}

A third study was conducted in six minks to investigate the bioavailability of SDZ and TMP following oral administration in feed. Minks were housed in metabolic cages, which are similar to conventional cages, except that they are slightly smaller, do not have a nest attached, and mink are fed using feed bowls in order to more precisely measure food intake. Upon $18 \mathrm{hr}$ of fasting (to ensure a uniform and rapid consumption of feed), each animal was provided with 190$240 \mathrm{~g}$ feed supplemented with SXD $\left(2.8 \mathrm{~g} / \mathrm{kg}\right.$ feed, Trimazin ${ }^{\circledR}$ Forte Vet., ScanVet Animal Health, Fredensborg, Denmark). The amount of feed was adjusted individually, to ensure each animal received the empirical dosage of $30 \mathrm{mg} / \mathrm{kg}$ (i.e. $5 \mathrm{mg} / \mathrm{kg}$ TMP and $25 \mathrm{mg} / \mathrm{kg}$ SDZ). Blood samples were collected from awake mink by nail clipping before and at 30, 60, $120 \mathrm{~min}$ and 6, 10, 15, 24, 48, and $72 \mathrm{hr}$ after feeding.

\subsection{Collection and processing of blood samples}

All blood samples (0.5-0.8 mL) were collected in capillary blood tubes (KABE LABORTECHNIK) containing a coagulant and a separating gel. The capillary tubes were kept at room temperature for $10 \mathrm{~min}$ to induce clot formation, and serum $(>150 \mu \mathrm{l})$ was collected and stored at $-80^{\circ} \mathrm{C}$ after centrifugation at $1,000 \mathrm{~g}$ for $10 \mathrm{~min}$.

\subsection{Anesthesia and analgesia}

After preoxygenation ( $90 \% \mathrm{O}_{2}$ for 8-10 min), sevoflurane (Sevoflo ${ }^{\circledR}$, Orion Pharma) was used for induction of anesthesia (8\% for $3 \mathrm{~min}$ and additional 2 min when the level of anesthesia was insufficient) in an induction chamber. A laryngeal mask (V-gel ${ }^{\circledR}$, Docsinnovent) was inserted and used for maintenance of anesthesia $(2.5 \%-5 \%$ sevoflurane for max. $3 \mathrm{hr}$, depending on monitored vital parameters). Heart rate, respiration rate, body temperature, noninvasive blood pressure, $\mathrm{O}_{2}$ saturation, hemoglobin in arterial blood, and endtidal $\mathrm{CO}_{2}$ were recorded every 15 min during anesthesia using pulse oximetry and a multifunction anesthesia monitor (Datex Ohmeda). In the first experiment, IV injection of SXD and withdrawal of the initial six blood samples were done during one continuous period ( $<3 \mathrm{hr}$ ) of anesthesia. The subsequent blood samples were collected under short-term (10-30 min) anesthesia at each time point. In the second experiment, anesthesia was used only during the first blood sampling $(t=0)$ and during SXD IV administration. Subsequent blood samples (at 12, 24, 48, 72 hr) were withdrawn from awake, entrapped minks by nail clipping. Minks were not subjected to anesthesia in the third experiment, as (a) SXD was administered via feed, and (b) all blood samples were collected by nail clipping from awake, entrapped minks.

As an analgesic, meloxicam (Metacam ${ }^{\circledR}$, Boehringer Ingelheim) was administered subcutaneously to all 22 animals $(0.2 \mathrm{mg} / \mathrm{kg}$, SID) 5-15 min before the first blood sampling. Ferric chloride hexa-hydrate 50\% (Sigma-Aldrich) was applied topically after nail clipping for hemostasis.

\subsection{Serum protein binding of SDZ and TMP}

Binding of SDZ and TMP to mink serum protein was determined by ultrafiltration (Villa, Prandini, Caloni, \& Carli, 1997). Prior to the study, $50 \mathrm{ml}$ pooled serum from 10 different minks was collected while pelting at a commercial farm. The serum was collected by heart puncture immediately after $\mathrm{CO}_{2}$-mediated euthanasia and stored at $-20^{\circ} \mathrm{C}$. Fresh stock solutions of $50 \mathrm{mg} / \mathrm{mL}$ SDZ (SigmaAldrich) in $1 \mathrm{M} \mathrm{NaOH}$ and $10 \mathrm{mg} / \mathrm{mL}$ TMP (Sigma-Aldrich) in DMSO were prepared. Final dilutions of $5,50,500 \mu \mathrm{g} / \mathrm{mL}$ for SDZ and 1, 10, $100 \mu \mathrm{g} / \mathrm{mL}$ for TMP were prepared by spiking thawed mink serum. In a control group, serum was replaced with PBS to measure the initial concentration of SDZ and TMP. Serum and control samples were incubated at $38^{\circ} \mathrm{C}$ for $60 \mathrm{~min}$ to mimic the body temperature of mink, followed by filtration using 30-kDa filter tubes (Amicon ${ }^{\circledR}$ Ultra-2, Merck Millipore), and centrifugation at $4000 \mathrm{~g}$ for $20 \mathrm{~min}$ at room temperature. Filtered aliquots were transferred to Eppendorf tubes and stored at $-80^{\circ} \mathrm{C}$ until analysis. Before their use, new filter tubes were washed once with $0.5 \mathrm{ml}$ of $0.1 \mathrm{M} \mathrm{NaOH}$, and then rinsed twice with $1.0 \mathrm{~mL}$ PBS to remove glycerin residues. Tubes were centrifuged at $7000 \mathrm{~g}$ for $20 \mathrm{~min}$ each time. After quantification of SDZ and TMP in each sample (see section 2.6.), a linear regression curve was used to fit the mean value of each concentration.

\subsection{Analysis of SDZ and TMP by LC-QTOF-MS}

A liquid chromatography (LC) with quadrupole time of flight mass spectrometry (QTOF-MS) detection was used for measuring the concentration of SDZ and TMP in serum samples from the animal 
experiments and in serum and PBS samples from the serum protein binding assay. The detailed procedure is described in Appendix S1. In brief, matrix-matched standard samples were prepared in blank serum at seven different concentration levels in the range of 0.05 $50 \mu \mathrm{g} / \mathrm{mL}$ for SDZ and 0.01-10 $\mu \mathrm{g} / \mathrm{mL}$ for TMP. The standard calibration curve was assessed at the beginning, after each 20 samples, and at the end of the sequence. Extracted ion chromatograms of $\mathrm{m} / \mathrm{z} 251.0597+273.0417 \pm 0.005 \mathrm{Da}(\mathrm{SDZ},+\mathrm{H}$ and $+\mathrm{Na})$ and $\mathrm{m} / \mathrm{z}$ $291.1452 \pm 0.005 \mathrm{Da}(\mathrm{TMP},+\mathrm{H})$ were constructed and integrated. No interfering peaks were observed at the retention times of the antimicrobials. Serum concentrations were calculated based on linear calibration curves constructed using $1 / \times$ weighing. As all samples were analyzed in one sequence, the inter-day precision is not relevant. The intra-day precision (CV\%) for samples was $<10 \%$. The lower limit of quantification (LLOQ) was $128 \mathrm{ng} / \mathrm{mL}$ for SDZ and $64 \mathrm{ng} / \mathrm{mL}$ for TMP.

\section{7 | Pharmacodynamic data}

Sulfamethoxazole-trimethoprim (SXT) MIC distributions for P. aeruginosa $(n=55)$ and S. delphini $(n=63)$ of mink origin were determined in a parallel project by broth microdilution according to the Clinical and Laboratory Standards Institute (CLSI, 2019). Isolates had been obtained from standard aerobic culture of various clinical specimens from mink in six European countries. Tentative ECOFFs (TECOFFs) for S. delphini $(0.25 \mathrm{mg} / \mathrm{L})$ and $P$. aeruginosa $(32 \mathrm{mg} / \mathrm{L})$ were determined by visual inspection and further regression modeling of MIC distributions (Turnidge, Kahlmeter, \& Kronvall, 2006; Nanett K. Nikolaisen, Personal communication, 22.01.2020). For E. coli, the existing EUCAST SXT ECOFF of $0.25 \mathrm{mg} / \mathrm{L}$ was used for dosage determination.

\section{8 | Pharmacokinetic analysis}

Initially, PK modeling was performed by nonlinear least-squares regression (classical two-stage) analysis in terms of clearance and volume of distribution (WinNonlin ${ }^{\circledR}$, Phoenix 8.0 software package). The individual serum concentrations of SDZ and TMP from nail and venous blood samples were fitted to mono-exponential (Equation 1) and biexponential (Equation 2) equations corresponding to a onecompartment and a two-compartment model, respectively.

$$
C(t)=\frac{\text { Dose }}{V} \times \operatorname{Exp}\left(-\frac{C L}{V} \times t\right)
$$

where $C(\mu \mathrm{g} / \mathrm{mL})$ is serum concentration at time $(t)$, dose $(\mathrm{mg} /$ $\mathrm{kg}$ ) is administered dose, $\mathrm{V}(\mathrm{mL} / \mathrm{kg})$ is volume of distribution, and $\mathrm{CL}$ $(\mathrm{mL} / \mathrm{hr} / \mathrm{kg})$ is body clearance.

$$
C(t)=A \times \operatorname{Exp}(-\alpha \times t)+B \times \operatorname{Exp}(-\beta \times t)
$$

where $A(\mu \mathrm{g} / \mathrm{mL})$ is intercept of distribution phase, $\alpha(1 / \mathrm{hr})$ is the first slope of the curve corresponding to the distribution phase, $B$ $(\mu \mathrm{g} / \mathrm{mL})$ is the intercept of the elimination phase, and $\beta(1 / \mathrm{hr})$ is the second slope of the curve corresponding to the elimination phase.

During the process of fitting, the data points were weighted by the inverse of the squared-fitted value weights. To minimize the sum of squared residuals of objective function (OFV), a Gauss-Newton optimization approach with Levenberg-Hartley modification was used. Determination of the best fit for each data set in terms of oneor two-compartmental model was based on visual inspection of the residual plots and Akaike's information criterion (AIC) (Yamaoka, Nakagawa, \& Uno, 1978). Geometric means and corresponding ranges were calculated for PK parameters obtained from the classical twostage analysis. The Wilcoxon signed-rank test was used to compare the effect of site of blood sampling (nail versus vein) and feeding status on PK parameters returned from the two-compartment model for SDZ and TMP.

In a second step, and because the data set was unbalanced, a population PK analysis using nonlinear mixed-effect models (NLME) (Phoenix ${ }^{\odot} 8.0$ software package) was performed on data obtained from the first two animal experiments to refine the value of parameters obtained with the two-step approach and to estimate the between-subject variability (BSV) of parameters (Bon et al., 2018; Mould \& Upton, 2012). Based on visual inspection of plots for all minks and using the two-step approach, the two-compartmental structural model was a priori selected for the population modeling. The population structural model was parameterized in terms of clearance and volume of distribution. The BSV, which is assessed by the variance of a parameter across individuals, was modeled using an exponential model (e.g. for clearance, Equation 3):

$$
\theta_{\text {clearance_i }}=\theta_{\text {tv_clearance }} \times \exp \left({ }_{\eta} i\right) \text { where } \eta \approx N\left(0, \omega^{2}\right)
$$

where $\theta_{\text {clearance i }}(\mathrm{mL} / \mathrm{hr} / \mathrm{kg})$ is the value of clearance in the ith mink, $\theta_{\text {tv_clearance }}$ is the typical population value of clearance, and $\eta_{i}$ is the deviation associated to the ith mink from the corresponding theta population value of clearance.

The shrinkage of random effects toward the means was calculated for the etas $(\eta)$ (Karlsson \& Savic, 2007). The random component of the parameter was deleted from the model, when computed shrinkage was high (>0.4). The BSV was estimated from the $\omega^{2}$ (variance), which has a log-normal distribution. The log-normal variance was converted to a coefficient of variation (CV\%) in the original scale (Equation 4).

$$
C V(\%)=100 \times \sqrt{\exp \left(\omega^{2}\right)-1}
$$

The residual component of random effects for parameters was estimated by using an additive and multiplicative error model (Equation 5) with residual error $(\varepsilon)$ having a mean of 0 and variance of $\sigma_{2}$.

$$
C(t)=f(\theta, \text { Time }) \times\left(1+\varepsilon_{1}\right)+\varepsilon_{2} \text { where } \varepsilon_{1} \sim N\left(0, \sigma_{1}^{2}\right) \text { and } \varepsilon_{2} \sim N\left(0, \sigma_{2}^{2}\right)
$$

where $\varepsilon_{1}$ is a multiplicative error term and $\varepsilon_{2}$ is an additive error term. 
The first-order conditional estimation extended least-squares (FOCE-ELS) engine was used for parameter estimation. For the precision of parameters, the bootstrap tool ( $n=30$ replicates) was used. This tool runs a series of model fits, each time using a random sampling, with replacement, from the original set of individuals. PK parameters from NLME were determined as typical values of a population with corresponding standard error (SE) and confidence intervals of estimates.

The covariate search tool (Cov. Srch. shotgun run mode) in Phoenix 8.0 was used to select the best set of covariates based on an automatically parallelized shotgun search to evaluate all the possible scenarios. It consisted of adding the covariates of blood sampling site and feeding status to the 16 possible combinations of four structural parameters and selecting the best possible combination, based on the reduction of the Bayesian information criterion (BIC).

In the final step, data obtained from nail blood samples from all experiments were simultaneously fitted to the two-compartmental model to obtain estimates for the structural parameters after IV and oral dosing. The structural model is presented in Figure 1. The statistical model was identical to the population model after IV dosing. Parameter estimation was done by the Laplacian engine, which is similar to FOCE-ELS but with a different approximation approach. The parameter precision was obtained by using the bootstrap tool $(n=30)$.

\section{9 | PKPD cutoff for TMP and SDZ}

The PKPD cutoff is the highest possible MIC for which a given percentage of animals (here 90\%) in the target population can achieve a critical value for the selected PKPD index (here fAUC/MIC of $24 \mathrm{hr}$ ) at a given dosage (Toutain et al., 2017). Using Monte Carlo simulation (MCS), a meta-population of 2,000 minks (i.e. of 2,000 serum disposition curves) was obtained by solving the population PK model after oral dosing (vide supra). The individual predicted concentration (IPRED) was simulated from the model, that is simulation of serum concentration without the error term from 0 to

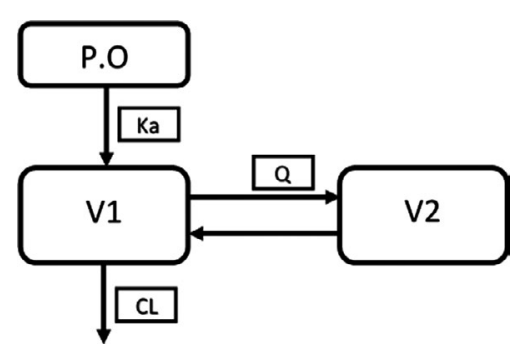

FIGURE 1 The two-compartmental structural model selected to analyze sulfadiazine and trimethoprim plasma concentrations. $\mathrm{CL}(\mathrm{mL} / \mathrm{hr} / \mathrm{kg})$, body clearance; $K_{\mathrm{a}}(1 / \mathrm{hr})$, absorption rate constant; P.O (per os), drug administration site; $Q$ (mL/hr/ $/ \mathrm{kg})$, inter-compartmental clearance; $V_{1}$ and $V_{2}(\mathrm{~mL} / \mathrm{kg})$, volumes of distribution of drug in the first and second compartment, respectively
$24 \mathrm{hr}$ postadministration, with a step of $0.5 \mathrm{hr}$. These 2,000 curves were analyzed using the noncompartmental tool of Phoenix 8.0 to compute the area under the concentration-time curves (AUC) and the corresponding $\mathrm{AAUC} / \mathrm{MIC}$ for different possible MICs with $f$ representing the free fraction of SDZ (0.72) or TMP (0.78) as determined in mink serum (section 2.5). These metrics were then analyzed with the statistical tool of Phoenix ${ }^{\circledR}$ to compute the quantile of interest (90th) for a PKPD target index of $24 \mathrm{hr}$ to establish the PKPD cutoff value.

\section{3 | RESULTS}

\subsection{Disposition and PK parameters of SDZ and TMP in serum}

Figure 2 illustrates the mean $( \pm$ SEM) concentrations of SDZ and TMP in serum after IV and oral administration of $30 \mathrm{mg} / \mathrm{kg}$ SXD (i.e. $25 \mathrm{mg} / \mathrm{kg}$ SDZ and $5 \mathrm{mg} / \mathrm{kg}$ TMP). The observed versus predicted plots and corresponding residual error versus predicted values of SDZ and TMP serum concentration under the one- and two-compartmental model obtained from two-stage analysis $\left(\right.$ WinNonlin ${ }^{\circledR}$ ) for nail and vein samples are presented in Appendix S2. Visual inspection of plots shows that the datasets fitted better in the two-compartmental model. The AIC decreased with the two-compartmental model by 10 and 8.15 points for SDZ and TMP, respectively. Based on visual inspection of plots and AIC, the twocompartmental model was selected. The estimated PK parameters from the two-stage analysis (WinNonlin ${ }^{\circledR}$ ) for nail and venous blood samples obtained from the two-compartmental model are presented in Table 1. Based on the Wilcoxon signed-rank test, there was no significant difference in estimated PK parameters between nail and venous blood samples, as well as between samples from fed versus nonfed animals ( $p>0.05$ ).

The results of the covariate search tool (Cov. Srch. Shotgun run mode) of the site of blood sampling (vein versus nail) and feeding status (fed versus fasted) after IV administration are presented in Appendix S3. There was no scenario that decreased the BIC more than the basic model with no covariates, thus confirming that the sampling site (nail versus vein) and feeding status (fed versus fasted) did not have any significant impact on PK parameters. Based on the outcome of two-stage analysis, the two-compartmental model was selected to simultaneously analyze the concentration-time data for nail blood samples after IV and oral dosing from all experiments. The observed versus individual prediction of serum concentrations (IPRED) and the plots of the visual predictive check (VPC) for different administration modalities are presented in Figures 3 and 4, respectively. The plots show good fit of data to the two-compartmental model for SDZ and TMP after IV and oral administration of SXD. The semi-logarithmic plots of observed and predicted serum concentration (latticed by individuals) vs. time after dosing are presented in Appendix S4. 
Sulfadiazine

(IV administration-Venous blood samples)
Sulfadiazine

(IV administration-Nail blood samples)
Sulfadiazine

(Oral administration-Nail blood samples)

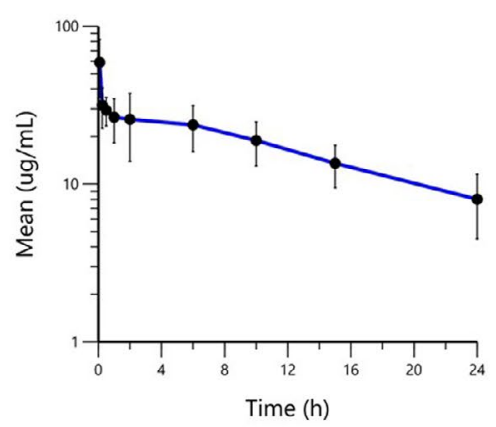

Trimethoprim

(IV administration-Venous blood samples)

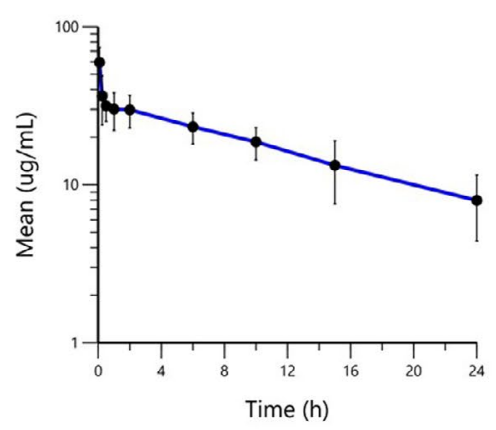

Trimethoprim

(IV administration-Nail blood samples)

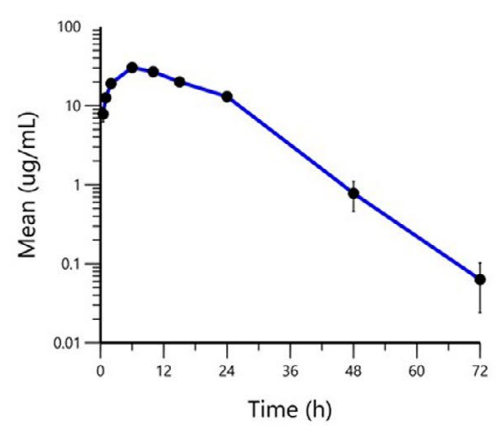

Trimethoprim

(Oral administration-Nail blood samples)


FIGURE 2 Mean $( \pm$ SEM) plasma concentration of sulfadiazine and trimethoprim from nail and vein samples, respectively, in semilogarithmic plots [Colour figure can be viewed at wileyonlinelibrary.com]

The estimations for PK primary and secondary parameters for SDZ and TMP are presented in Table 2. The half-life of absorption $\left(K_{\mathrm{a}-\mathrm{HL}}\right)$ was 4.8 and $1.5 \mathrm{hr}$ for SDZ and TMP, respectively. The bioavailability $(F)$ after oral dosing of SXD was complete for SDZ and $34.3 \%$ for TMP. The body clearance $(C L)$ for SDZ and TMP was different, that is 36.2 and $512.3 \mathrm{~mL} / \mathrm{kg} / \mathrm{hr}$, respectively. The elimination half-lives $\left(\beta_{\mathrm{HL}}\right)$ of SDZ and TMP were 8.6 and $4.7 \mathrm{hr}$, respectively. The multiplicative components of residual error for the two drugs reflecting both analytical error and departure to the model were low, illustrated by the CV of $15 \%$ and $20 \%$ for SDZ and TMP, respectively. The exponential random components were removed for $\mathrm{V}_{1}$ and $\mathrm{Q}$ in SDZ and for $\mathrm{Q}$ in TMP due to high shrinkage values making estimations of these parameters impossible. The BSV of remaining random components in both drugs were low (Table 2).

\subsection{Serum protein binding of SDZ and TMP}

The free fractions of SDZ and TMP were obtained as the ratio of the slope coefficient $\mathrm{b}$ of the spiked serum curve to the control solution curve, multiplied by 100 . The free fractions of SDZ and TMP in serum were $72 \%$ and $78 \%$, respectively.

\subsection{PKPD cutoff and dosage regimen of SDZ and TMP in mink}

Based on previous studies, the $\mathrm{AAUC} / \mathrm{MIC}$ was deemed the appropriate PKPD index for SXD (Asín-Prieto et al., 2015; Cheng et al., 2009). A 24-hr target value for the PKPD index was selected arbitrarily. In other words, it was assumed that, when administered individually, SDZ and TMP exhibit sufficient antimicrobial efficacy if the average free plasma concentration is at least equal to the MIC over $24 \mathrm{hr}$. Thus, the primary goal of MCS was to find the highest MIC of TMP and SDZ that the average serum concentration of both drugs is equal to in $90 \%$ of minks with the currently used dosage regimen ( $30 \mathrm{mg} / \mathrm{kg}$, i.e. $5 \mathrm{mg} / \mathrm{kg}$ for TMP and $25 \mathrm{mg} /$ $\mathrm{kg}$ for SDZ). Results of the MCS are presented in Table 3, showing that the average AUC ratio between TMP and SDZ for the quantile of 90 is $1: 158$. Also, the table shows that after oral dosing of $5 \mathrm{mg} / \mathrm{kg}$ of TMP, and for the fAUC/MIC as a PKPD index, $90 \%$ 
TAB LE 1 Estimated parameter values with the two-compartmental model in a classical two-stage analysis for SDZ and TMP obtained from nail and vein samples following IV administration in minks

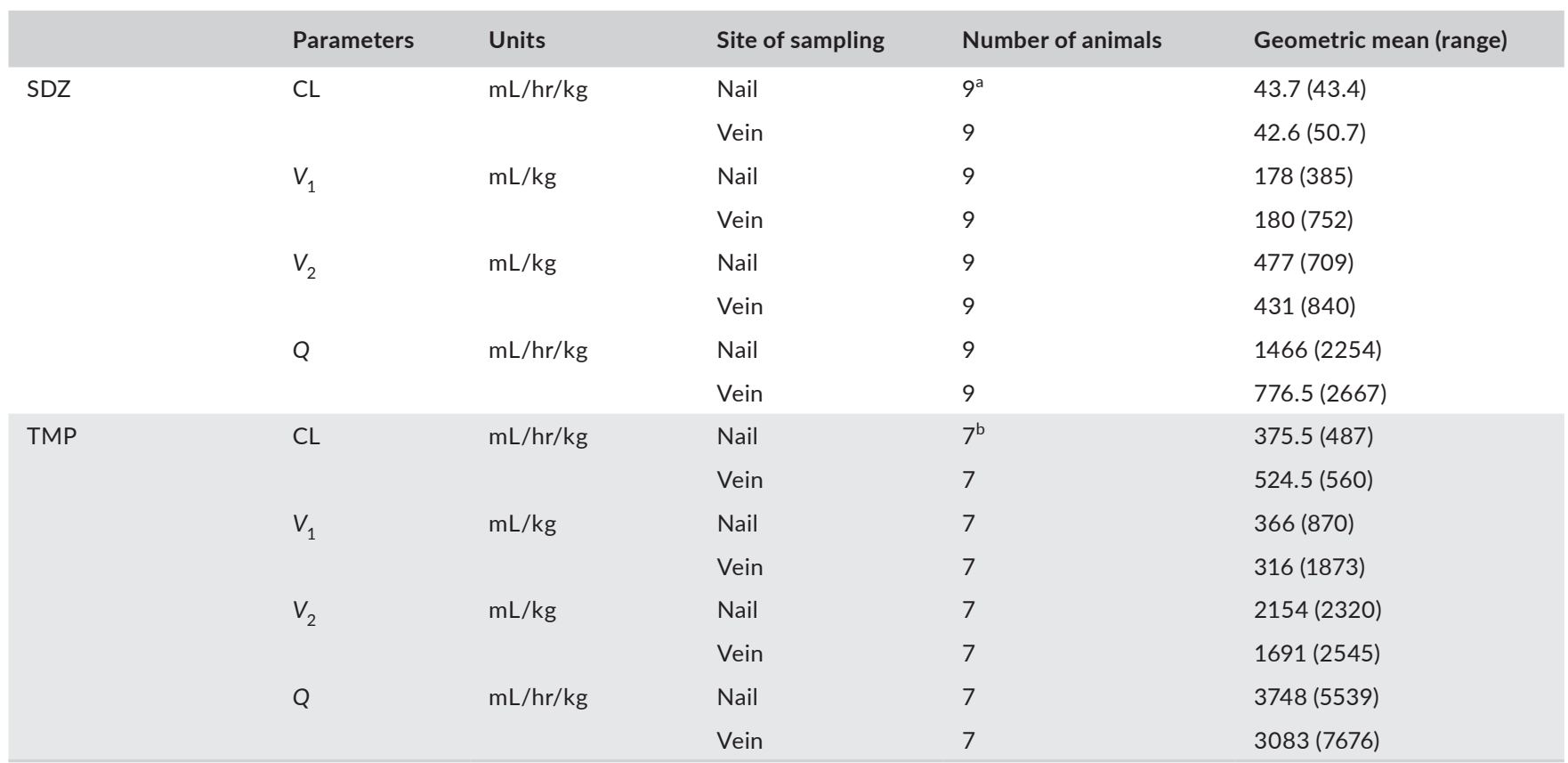

Abbreviations: $C L$, body clearance; $Q$, inter-compartmental clearance; SEM, standard error of the mean; $V_{1}$ and $V_{2}$, volumes of distribution in the central and peripheral compartment, respectively.

${ }^{\mathrm{a}}$ From $10 \mathrm{IV}$ datasets, one dataset failed to fit to the model.

${ }^{\mathrm{b}}$ From 10 IV datasets, three datasets failed to fit to the model.

of minks will attain a free plasma concentration of TMP above 0.062 and $0.125 \mathrm{mg} / \mathrm{L}$ for 32.7 and $16.36 \mathrm{hr}$, respectively. For SDZ, after oral dosing of $25 \mathrm{mg} / \mathrm{kg}, 90 \%$ of minks will attain a free plasma concentration of SDZ above 16 and $32 \mathrm{mg} / \mathrm{L}$ for 28 and $14 \mathrm{hr}$, respectively. Hence, the PKPD cutoffs for TMP and SDZ were 0.062 and $16 \mathrm{mg} / \mathrm{L}$, respectively, to ensure an fAUC/ MIC above $24 \mathrm{hr}$.

\section{4 | DISCUSSION}

The aims of this study were to investigate, using PK/PD concepts, the efficacy of the current empirical SXD dosage regimen $(30 \mathrm{mg} /$ $\mathrm{kg}$ ) for mink, and secondarily to produce data supporting development of clinical breakpoints against pathogens in this species. Currently, SXD is used off-label to manage various infections in mink caused by pathogens such as E. coli, P. aeruginosa, and S. delphini. Based on our experience, mink veterinarians mostly use a dosage regimen of $30 \mathrm{mg} / \mathrm{kg}$ body weight once daily in feed, corresponding to $5 \mathrm{mg} / \mathrm{kg}$ TMP and $25 \mathrm{mg} / \mathrm{kg}$ SDZ. This dosage regimen is not evidence-based but has been adapted from SPCs of commercial SXD products licensed for major domestic species such as cattle or pig. In order to develop a mink-specific dosage regimen, PK and PD data must be analyzed taking into account potential synergism of sulfonamides and TMP. In that regard, early in vitro checkerboard experiments demonstrated that a ratio of 1:15-1:22 between TMP and sulfonamides provided an optimal synergistic effect between the two drugs against numerous bacterial species (Bushby, 1980). In humans, extravascular administration of TMP and sulfonamides in a 1:5 ratio is known to result in such optimal therapeutic plasma ratios. Also, in humans, SMX has been selected as the preferred sulfonamide for potentiation of TMP because of the similarity of their half-life ( $10 \mathrm{hr}$ ), which ensures parallel decay of the two drugs in the human body and a constant in vivo plasma ratio of $\sim 1: 19$ during treatment (Van Miert, 1994). In veterinary medicine, all these essential rational grounds have been ignored with the human recipe being copied and blindly pasted to domestic species, thereby failing to appreciate the possible difference in $\mathrm{PK}$ of the drugs between animals and humans. Disposition data of TMP and SDZ in different animal species upon IV and oral administration of 1:5 formulations reveal notable inter-species differences in PK parameters (Table 4). In horse, dog, and broiler, the AUC ratios between TMP and SDZ were $1: 30,1: 31$, and $1: 50$, respectively, that is reasonably close to the ideal ratio of 1:15-1:22 (Baert, De Baere, Croubels, \& De Backer, 2003; Gustafsson et al., 1999; Sigel et al., 1981; Van Duijkeren et. al., 2002). In contrast, this ratio was 1:139 and 1:124 in sheep and ostrich, respectively (Abu-Basha, Gehring, Hantash, Al-Shunnaq, \& Idkaidek, 2009; Batzias, Delis, \& Koutsoviti-Papadopoulou, 2005a, 2005b). Also, the oral administration of TMP and another sulfonamide, sulfadoxine, in cattle resulted in a very high AUC ratio, namely 1:134 (Greko et al., 2002). In this context, we attempted to assess the validity of the SXD dosage regimen currently used in mink with 


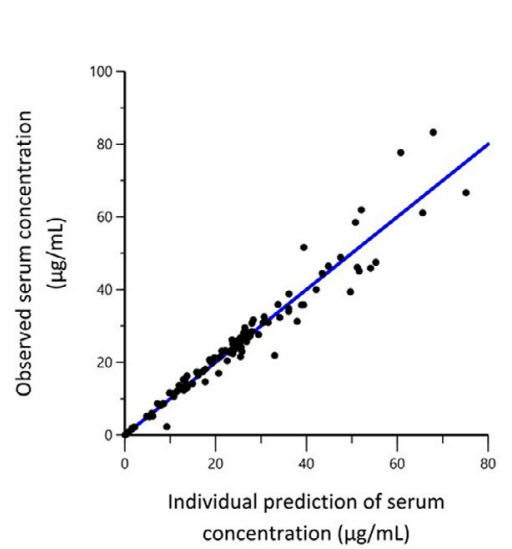

\section{Sulfadiazine}

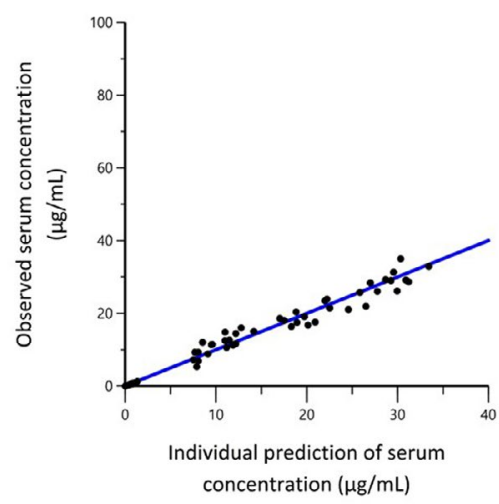

Trimethoprim

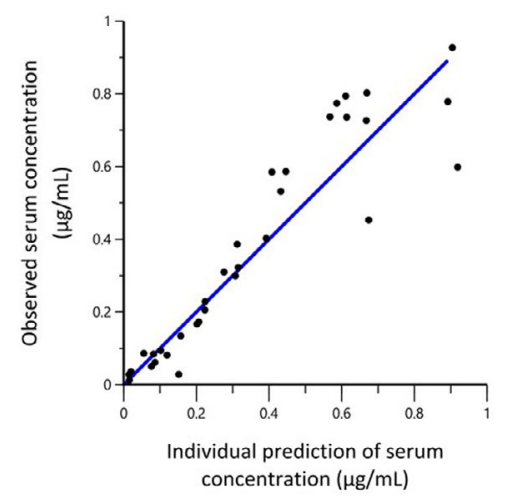

FIGURE 3 Plots of the observed serum concentrations $(\mu \mathrm{g} / \mathrm{mL}$ ) versus individual predicted serum concentrations of sulfadiazine and trimethoprim after IV (left) and oral dosing (right). Individual predictions were obtained by setting random effects to the "post hoc" or empirical Bayesian estimate of the random effects for individuals from which the observed plasma concentration was prepared. Thus, the plots show observed versus fitted values of the model function [Colour figure can be viewed at wileyonlinelibrary.com] generic recommendations for TMP and sulfonamides in combination. Our first task was to compute the ratio of TMP and SDZ in mink plasma and to assess how similar the terminal half-lives of these two agents are. The AUC as a surrogate for plasma concentration is controlled by body clearance and bioavailability. Following IV administration of $30 \mathrm{mg} / \mathrm{kg}$ SXD (5 mg/kg TMP and $25 \mathrm{mg} / \mathrm{kg} \mathrm{SDZ)}$ in mink, the body clearance of TMP was 10.8 times higher than SDZ (410 mL/kg/hr compared to $38 \mathrm{~mL} / \mathrm{kg} / \mathrm{hr}$ ). After oral administration of the same dosage in mink, the bioavailability was complete (99.6\%) for SDZ but only 34\% for TMP, leading to an AUC ratio of 1:164 for TMP and SDZ. As only the free fraction of a drug is bacteriologically active, the AUC ratio was corrected to 1:158 after taking into account the extent of plasma protein binding (22 and $28 \%$ for TMP and SDZ, respectively). This ratio is very different from the claimed optimal target ratio of 1:19 (Van Miert, 1994). In addition, the half-lives of TMP and SDZ in mink were different (4.7 and $8.7 \mathrm{hr}$, respectively), so the 1:158 ratio between the two drugs will not persist during SXD therapy. Taken together, the very high TMP:SDZ plasma ratio and the distinct half-lives of the two drugs in mink reflect that the SXD combinational product does not meet the generic recommendations for this antimicrobial class.

After assessing the ratio of TMP and SDZ, we assessed the pertinence of the SXD dose currently used in mink. We first assimilated our computed PKPD cutoffs of 0.062 and $16 \mathrm{mg} / \mathrm{L}$ for TMP and SDZ, respectively, to possible clinical breakpoints, that is we assumed that these cutoffs correspond not only to the MICs that can be targeted in $90 \%$ of mink, but that they also correspond to MICs for which clinical efficacy can be ensured when each substance acts alone. Considering the SXT ECOFF for E. coli $(0.25 \mathrm{mg} / \mathrm{L})$ and the TECOFF for $S$. delphini $(0.25 \mathrm{mg} / \mathrm{L})$, which represent TMP concentrations when tested in combination with SMX at a 1:19 ratio, it appears that the TMP component of SXT cannot ensure clinical efficacy against all wild-type isolates on its own. The same conclusion can be made for SDZ alone, because the TECOFF of another sulfonamide, SMX, in E. coli and S. delphini was recently determined to be 64 and 128 , respectively (Nanett K. Nikolaisen, Personal communication, 22.01.2020).

These calculations are associated with uncertainty, as they are based on separate computations for SDZ and TMP. As these two drugs are used in combination, we sought to adjust their PKPD cutoffs assuming an expected synergy against the mink target pathogens $E$. coli and S. delphini. For this purpose, the optimal ratio between TMP and SDZ for exerting maximum synergy against target pathogens should be considered. For E. coli, Ekström, Forsgren, Örtengren, and Bergan (1979) quantified the effect of TMP and SDZ using in vitro checkerboard assays and found an optimal synergistic effect using a 1:10-1:20 ratio between TMP and SDZ. With this ratio, the MICs of these drugs in combination decreased 5.0 and 5.4 times compared to the individual MICs for TMP and SDZ, respectively. With a ratio of $1: 40$, the MICs of TMP and SDZ in 


\section{Sulfadiazine}
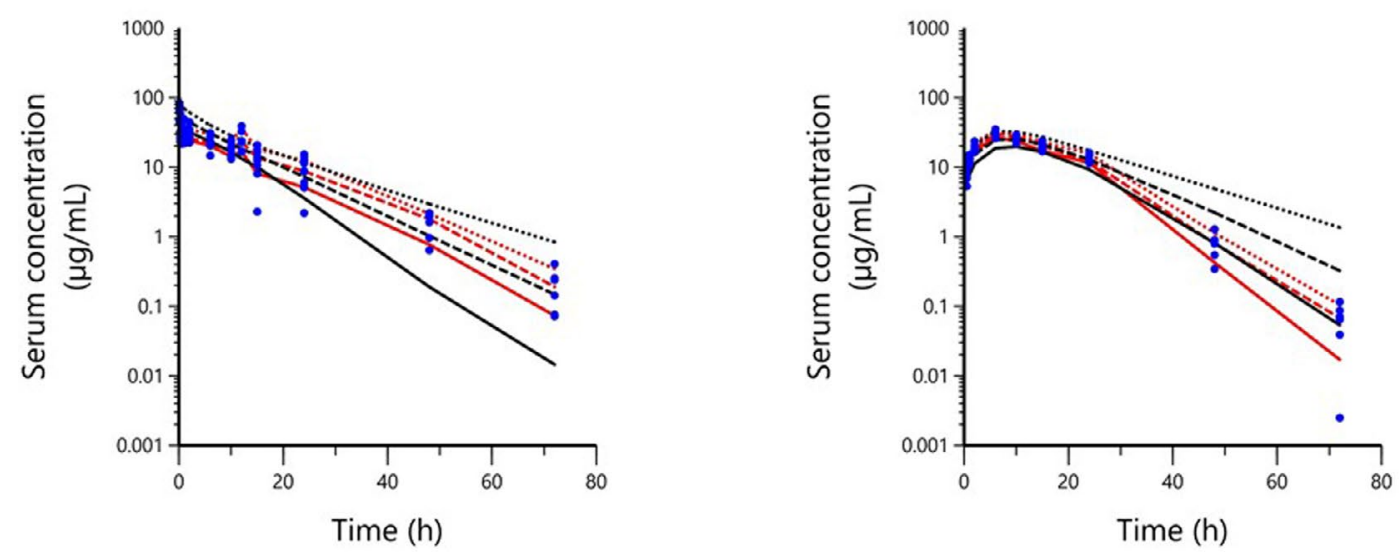

\section{Trimethorpim}
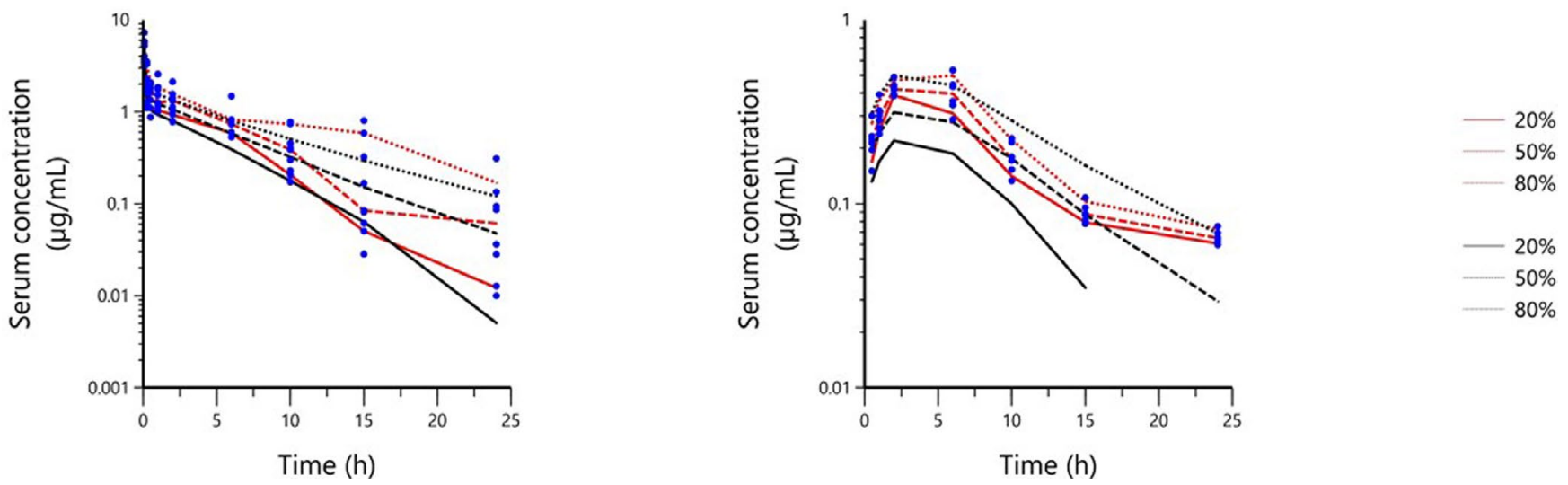

FIGURE 4 Visual predictive check (VPC) for sulfadiazine (top) and trimethoprim (bottom) after IV (left) and oral (right) dosing. The VPC diagnostic plots illustrate the observed (red); 20, 50, and 80\% percentiles superimposed with the predictive check percentiles (black); 20, 50, and $80 \%$ that were computed using Monte Carlo simulation over the observed serum concentrations (blue symbols) [Colour figure can be viewed at wileyonlinelibrary.com]

combination decreased 4.8 and 1.9 times, respectively. No prior studies have investigated a potential synergistic effect of TMP and SDZ against $S$. delphini, although for $S$. aureus the optimal synergistic ratio was reported to be also between 1:10 and 1:20, with even higher MIC reductions than for E. coli (Bushby \& Hitchings, 1968). Although these studies did not test the 1:158 drug ratio we detected, it appears that ratios above 1:20 promote the effect of TMP to a higher extent than SDZ. Furthermore, in vivo TMP is more likely to be boosted by SDZ than the other way around because the half-life of TMP is much lower than for SDZ. In other words, TMP is not present in the later phases of treatment; hence, it cannot boost the effect of SDZ over the entire dosing interval. Based on these considerations, we speculate that, due to anticipated synergy, the PKPD cutoff of TMP may be upregulated fivefold to $0.312 \mathrm{mg} / \mathrm{L}$. With this in mind, the PKPD cutoffs for TMP and SDZ will be 0.312 (adjusted) and $16 \mathrm{mg} / \mathrm{L}$ (nonadjusted), respectively. The former of these values is above the corresponding TECOFF in E. coli and
S. delphini; hence, SXD at the oral dosage of $30 \mathrm{mg} / \mathrm{kg}$ once a day is likely to be efficient against wild-type strains of these pathogens. It should be noted that our dosage calculations are based on the currently available veterinary SXD formulations with $5 \mathrm{mg} / \mathrm{kg}$ TMP and $25 \mathrm{mg} / \mathrm{kg}$ SDZ. These formulations provide much higher than needed levels of SDZ in mink plasma. Based on our computations, a formulation with $5 \mathrm{mg} / \mathrm{kg}$ TMP and $3 \mathrm{mg} / \mathrm{kg}$ SDZ would - at least for part of the dosing interval - lead to the optimal 1:19 ratio of the two drugs in mink plasma and would therefore be more appropriate. Optimization could also be done by replacing SDZ with another sulfonamide exhibiting the same kinetics as TMP in mink. Ensuring a similar half-life of the two drugs in combination would help ensure an ideal plasma ratio, and thereby synergism, for a longer part of the dosage interval.

Although $P$. aeruginosa is known to be intrinsically resistant to folate pathway inhibitors (Köhler et al., 1996), it is a common practice in Denmark to use SXD against mink hemorrhagic pneumonia caused 
TAB LE 2 Population bootstrap estimation of primary (A) and secondary parameters (B) of SDZ and TMP with corresponding precisions returned from the two-compartmental model following IV and oral administration

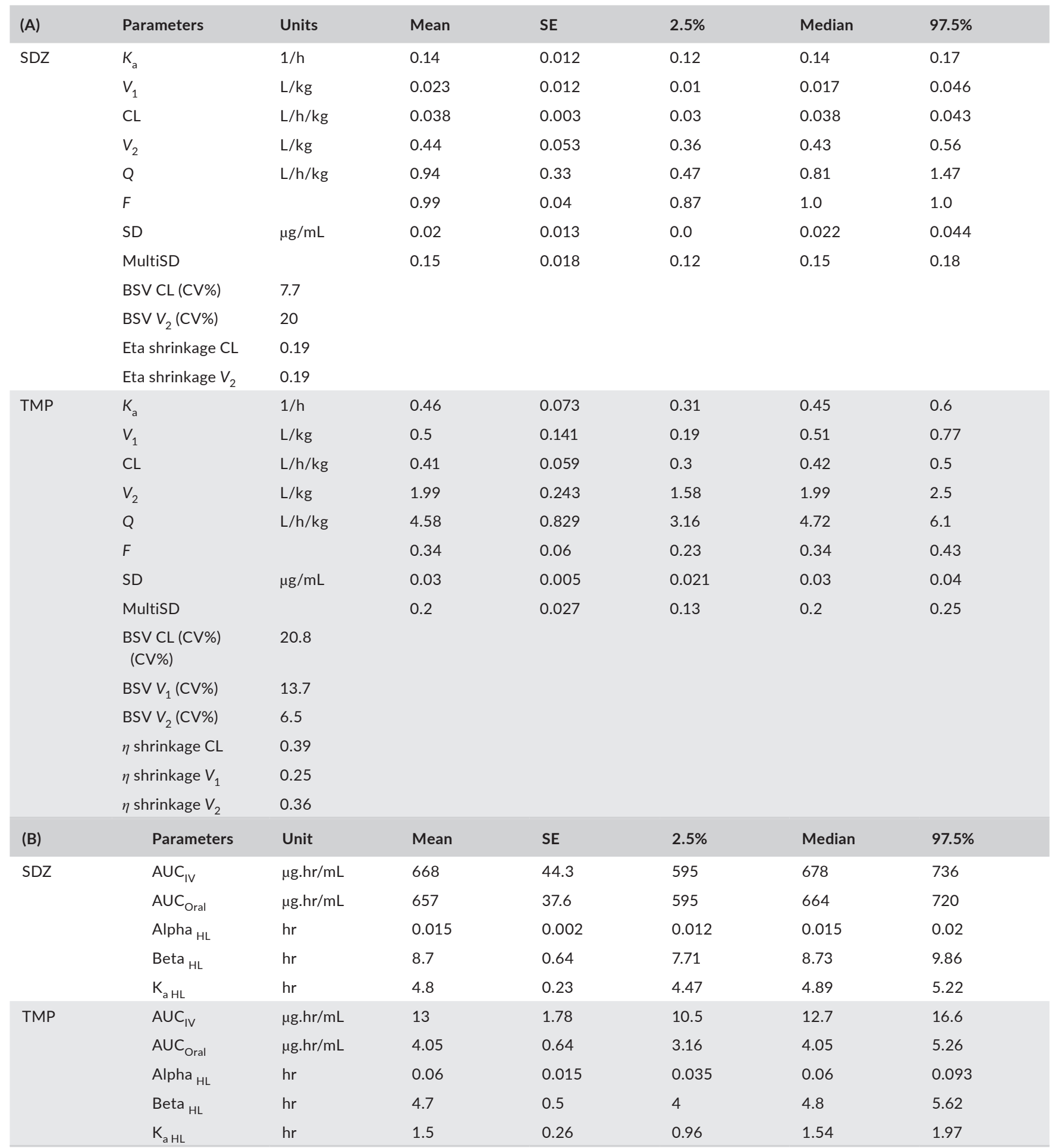

Abbreviations: $\mathrm{Alpha}_{\mathrm{HL}}$ and Beta $\mathrm{HL}_{\text {, }}$, half-life of distribution and elimination phase respectively; $\mathrm{AUC}_{\mathrm{IV}}$ and $\mathrm{AUC}_{\text {Oral, }}$, area under the concentrationtime curve after IV and oral dosing, respectively; BSV, between-subject variability of random components; CL, body clearance; CV, coefficient of variation; $F$, bioavailability for which an ilogit transformation was used to avoid an estimate higher than $1 ; K_{a}$ HL, absorption half-life; $K_{a}$, absorption rate constant; MultiSD, multiplicative error term; $Q$, inter-compartment clearance; SD, additive error term; SE, standard error; $V$, volume of distribution in the central compartment; $V_{2}$, volume of distribution in the peripheral compartment.

SE is standard error of estimate, Shrinkage refers to the BSV in the model, $\eta$-shrinkage is calculated as 1-SD ( $\eta) / \omega$ where $\eta$ are the BSV terms and $\omega$ is the population model estimate of the standard deviation in $\eta$. When data are very informative, $\eta$-shrinkage is zero, whereas it moves toward 1 when data are less informative. For the present paper, a shrinkage lower than 0.4 has been considered as acceptable with the corresponding BSV being reported. 
TABLE 3 The ratio of $f A U C / M I C$ for different SDZ and TMP MICs

\begin{tabular}{|c|c|c|c|c|}
\hline \multirow[b]{2}{*}{ MIC (mg/L) } & \multicolumn{2}{|l|}{ SDZ } & \multicolumn{2}{|l|}{ TMP } \\
\hline & $\begin{array}{l}\text { Q90 fAUC } \\
\text { ( } \mu g . h r / m L)\end{array}$ & $\begin{array}{l}\text { fAUC/ } \\
\text { MIC (hr) }\end{array}$ & $\begin{array}{l}\text { Q90 fAUC } \\
\text { ( } \mu \mathrm{g} \cdot \mathrm{hr} / \mathrm{mL})\end{array}$ & $\begin{array}{l}\text { fAUC/ } \\
\text { MIC (hr) }\end{array}$ \\
\hline 0.031 & 324.3 & 10377.9 & 2.05 & 65.4 \\
\hline $0.062^{*}$ & 324.3 & 7206.9 & 2.05 & 32.72 \\
\hline $0.125^{*}$ & 324.3 & 3603.5 & 2.05 & 16.36 \\
\hline 0.25 & 324.3 & 1801.7 & 2.05 & 8.18 \\
\hline 0.5 & 324.3 & 900.9 & 2.05 & 4.09 \\
\hline 1 & 324.3 & 450.4 & 2.05 & 2.04 \\
\hline 2 & 324.3 & 225.2 & 2.05 & 1.02 \\
\hline 4 & 324.3 & 112.6 & 2.05 & 0.51 \\
\hline 8 & 324.3 & 56.3 & 2.05 & 0.26 \\
\hline $16^{*}$ & 324.3 & 28.1 & 2.05 & 0.128 \\
\hline $32^{*}$ & 324.3 & 14.1 & 2.05 & 0.064 \\
\hline 64 & 324.3 & 7.04 & 2.05 & 0.032 \\
\hline
\end{tabular}

Note: The AUC is area under the serum concentration-time curve obtained from 2,000 drug disposition curves by MCS. Q90 is the $90 \%$ target attainment rate indicating the value of AUC that can be achieved in $90 \%$ in mink population. $f$ shows the free drug concentration. The bold value indicates the value of $\mathrm{AAUC} / \mathrm{MIC}(\mathrm{hr})$ showing the duration that drug concentration approximates the MIC for $24 \mathrm{~h}$. The MICs corresponding to bold values are marked by asterisks.

by this organism. Our results confirm this intrinsic resistance, as the SXD TECOFF of $64 \mathrm{mg} / \mathrm{L}$ indicates that exceedingly high doses of TMP and SDZ would be required to achieve a therapeutic effect in mink. In addition, $P$. aeruginosa can produce biofilm in patients' airways, thus further precluding antimicrobial agents from reaching lung pathogens at therapeutic concentrations (Drenkard, 2003; Høiby et. al., 2010). Taken together, the current practice of using SXD against hemorrhagic pneumonia in mink caused by $P$. aeruginosa cannot be recommended.

Ideally, clinical data based on the dosage of $30 \mathrm{mg} / \mathrm{kg}$ are required to establish mink-specific clinical breakpoints of SXD for E. coli and S. delphini infections. In the absence of such data, the determined PKPD cutoffs and the pathogen-specific (T)ECOFFs should be considered as an alternative for CBPs (Toutain et al., 2017). For the current dosage of $30 \mathrm{mg} / \mathrm{kg}$, the adjusted PKPD cutoff for TMP (0.312 $\mathrm{mg} / \mathrm{L})$ and the nonadjusted PK/PD cutoff for SDZ (16 mg/L) may be considered along with (T)ECOFFs when breakpoint-setting committees such as VetCAST determine CBPs for target pathogens.

In the first study, we compared PK results for mink that had been fasted for 2 versus $24 \mathrm{hr}$ prior to administration of SDZ. The underlying reason is that feed has previously been shown to impact not only oral drug absorption, but also PK parameters (e.g. body clearance) of various drugs following IV administration (Bai, Walle, \& Walle, 1985; Elvin, Cole, Pieper, Rolbin, \& Lalka, 1981). Importantly, feeding status did not influence PK parameters in our study, but we cannot conclude that this will always be the case, as mink feed can vary a lot depending on the availability and price of components such as slaughter offal. In the first study, we also compared PK results for blood obtained from the cephalic vein and blood from nails. Nail blood is a mixture of venous and arterial blood and therefore not necessarily representative of venous blood, which is typically used for assessing drug concentrations prior to PK modeling. Fortunately, there was no difference in PK results for the two sampling sites (see Appendix S3), allowing us to take only nail blood in the 2nd and 3rd in vivo study, and thereby avoiding the expensive and laborious anesthesia prior to sampling.

One limitation of this study is that we chose the target AUC/ MIC ratio of $24 \mathrm{hr}$ arbitrarily, but this was necessary due to the absence of prior in vitro or in vivo studies supporting an appropriate PKPD target. Our dosage calculation is associated with some uncertainty, as it is based on an assumption of synergy between TMP and SDZ, and we cannot be certain of optimal synergy at the 1:158 serum concentration ratio calculated for these drugs. Furthermore, in the absence of SDZ MIC data for mink pathogens, we refer to SMX TECOFFs. This is likely not problematic for our dosage calculations, as Sadaka, Kanellos, Guardabassi, Boucher, and Watts (2017) concluded that these two sulfonamides in combination with TMP yield similar MIC results, and SXT may act as a surrogate for SXD when testing susceptibility of equine streptococci (Sadaka et al., 2017). Another potential limitation is our use of an analgesic and anesthesia, which was necessary for practical and ethical reasons. The use of such drugs may influence the disposition of TMP and SDZ due to alterations of biological functions like cardiac output and blood flow to internal organs (Nimmo \& Peacock, 1988). Although this evidence relies on human studies, we cannot exclude that meloxicam and sevoflurane affected SDZ disposition in mink and consequently our results. A final limitation is our use of frozen serum for the protein binding experiment. This was necessary, as we did not have access to fresh serum, but it is possible that freezing altered the affinity of SDZ to proteins (Banker \& Clark, 2008).

In conclusion, this study indicates that the current oral dosage of $30 \mathrm{mg} / \mathrm{kg}$ SXD would be sufficient to combat infections caused by wild-type E. coli and S. delphini in mink. Follow-up in vivo studies are recommended to further validate this dosage regimen in a clinical setting. The PKPD cutoffs of 0.062 and $16 \mathrm{mg} / \mathrm{L}$ for TMP and SDZ individually, and anticipated $0.312 \mathrm{mg} / \mathrm{L}$ for TMP when used in combination, should be considered along with ECOFFs for future determination of CBPs for mink pathogens. The current use of SXD against $P$. aeruginosa pneumonia cannot be recommended, as high enough concentrations are unlikely to be achieved following systemic treatment.

\section{ACKNOWLEDGEMENT}

The authors would like to thank Mette Fertner (Kopenhagen Fur), Julie Melsted Birch (University of Copenhagen), Mattia Pirolo (University of Copenhagen), Anne Sofie Vedsted Hammer (University of Copenhagen), Connie Frank Matthiesen (University of Copenhagen), Ann-Mona Kulsø Larsen (Henrik Nordgaard Hansen), and the Section for Experimental Animal Models at the Department 

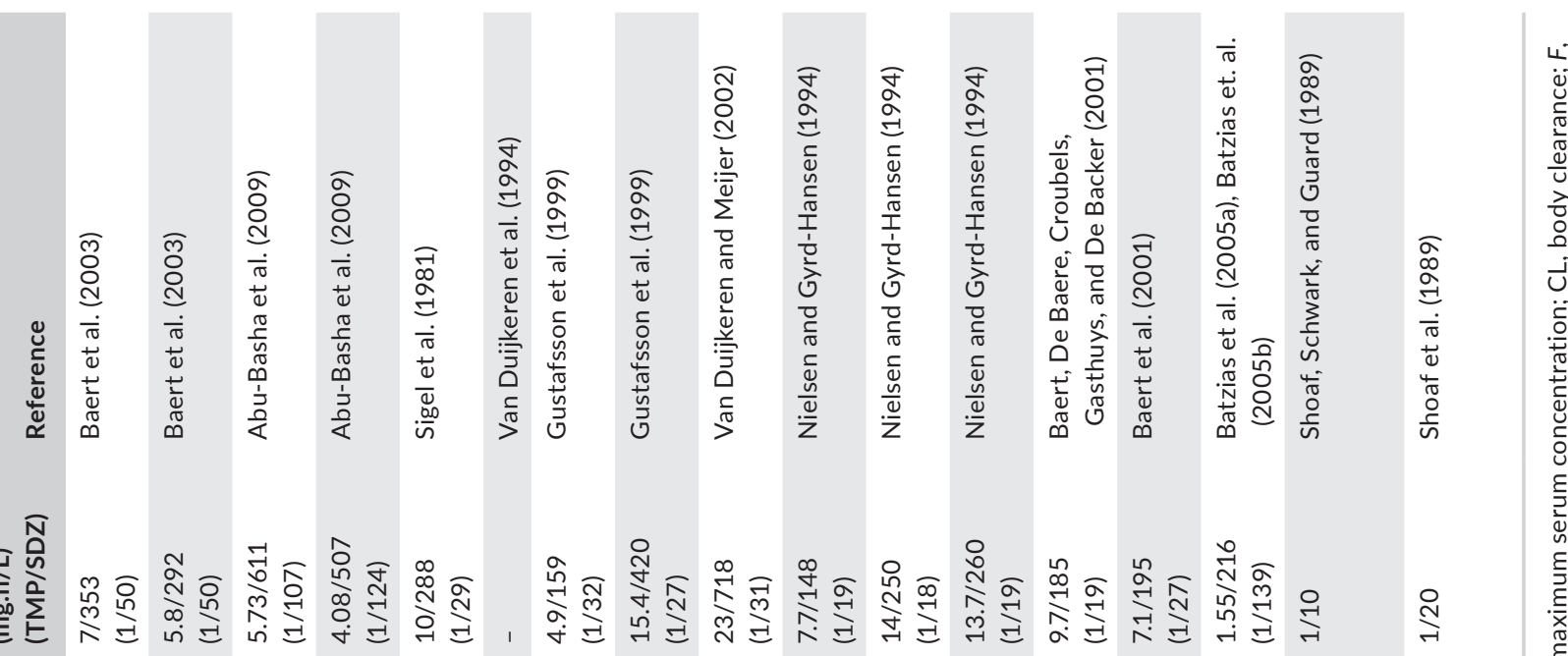

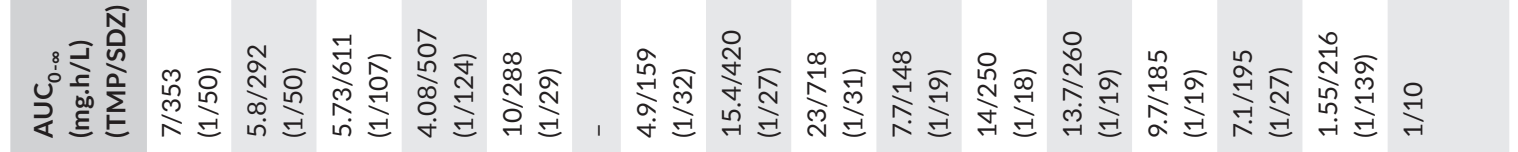

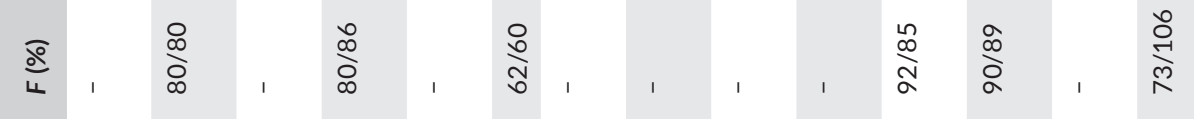

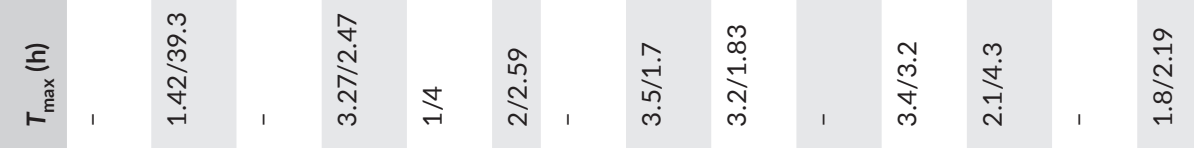

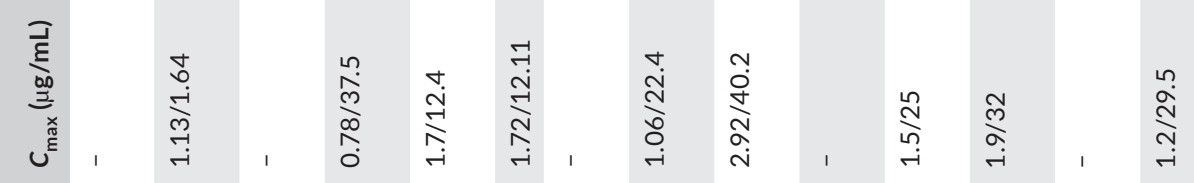

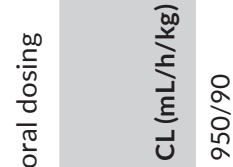

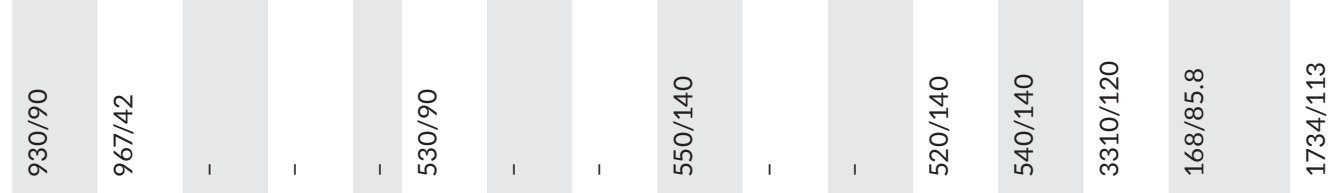

$\frac{\substack{0 \\ \frac{\pi}{\pi} \\ \geq}}{2}$

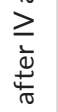

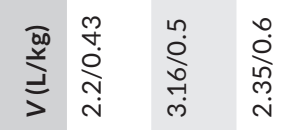

in

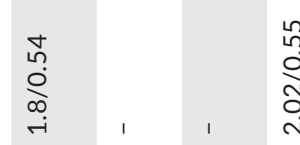

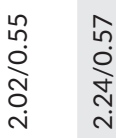

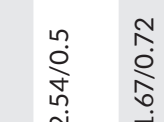

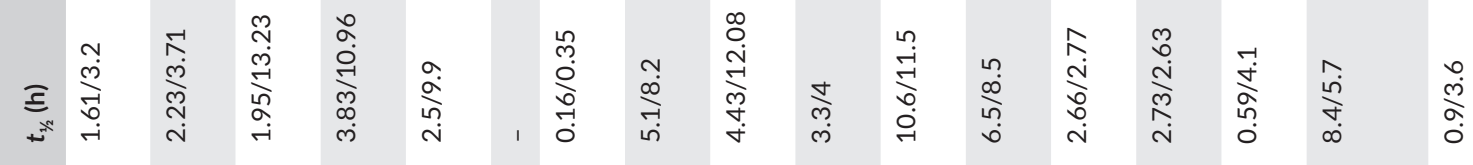

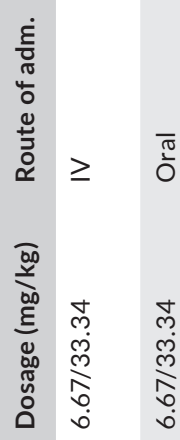

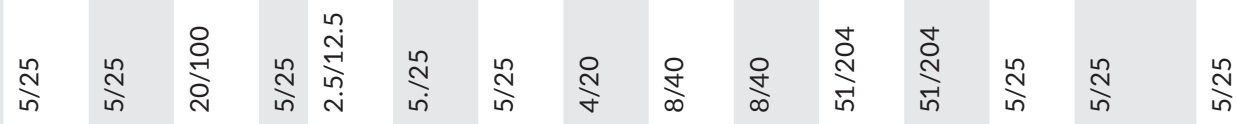

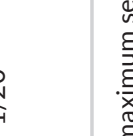

$\stackrel{5}{a}$

$\sum_{i}$

告

离

$\underset{\frac{\pi}{\pi}}{\frac{\pi}{\pi}}$

$\frac{\pi}{2}$

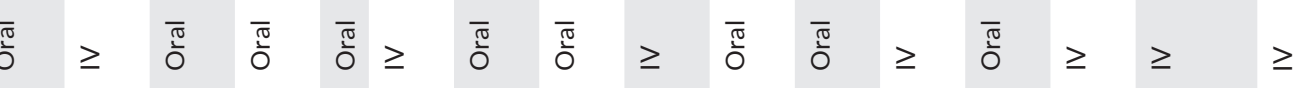

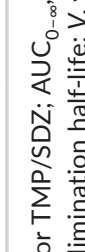


of Veterinary and Animal Sciences, University of Copenhagen, for their assistance with animal experiments. The work was funded by the research fund for the Danish fur breeder association (Dansk Pelsdyravlerforenings Forskningsfond) and Innovation Fund Denmark [grant number 5189-00060B].

\section{CONFLICT OF INTEREST}

The authors declare no conflict of interest.

\section{AUTHORS CONTRIBUTIONS}

AAR provided raw PK data and drafted the manuscript. NKN and TS provided PD data. NKN, SGH, TS, PD, and AAR conducted animal experiments. HHP was responsible for anesthesia and blood sampling in animal experiments. HLF conducted quantification and analytical processes of blood samples. PL-T and AAR performed modeling and analysis. PD and TS supervised the project. All authors critically reviewed the manuscript.

\section{ORCID}

Amir Atabak Ronaghinia (iD https://orcid. org/0000-0002-7041-8758

Pierre-Louis Toutain iD https://orcid.org/0000-0002-8846-8892

\section{REFERENCES}

Abu-Basha, E. A., Gehring, R., Hantash, T. M., Al-Shunnaq, A. F., \& Idkaidek, N. M. (2009). Pharmacokinetics and bioavailability of sulfadiazine and trimethoprim following intravenous, intramuscular and oral administration in ostriches (Struthio camelus). Journal of Veterinary Pharmacology and Therapeutics, 32(3), 258-263. https:// doi.org/10.1111/j.1365-2885.2008.01036.x

Asín-Prieto, E., Rodríguez-Gascón, A., \& Isla, A. (2015). Applications of the pharmacokinetic/pharmacodynamic (PK/PD) analysis of antimicrobial agents. Journal of Infection and Chemotherapy, 21(5), 319-329. https://doi.org/10.1016/j.jiac.2015.02.001

Baert, K., De Baere, S., Croubels, S., \& De Backer, P. (2003). Pharmacokinetics and oral bioavailability of sulfadiazine and trimethoprim in broiler chickens. Veterinary Research Communications, 27(4), 301-309.

Baert, K., De Baere, S., Croubels, S., Gasthuys, F., \& De Backer, P. (2001). Pharmacokinetics and bioavailability of sulfadiazine and trimethoprim (trimazin $30 \%$ ) after oral administration in non-fasted young pigs. Journal of Veterinary Pharmacology and Therapeutics, 24(4), 295298. https://doi.org/10.1046/j.1365-2885.2001.00337.x

Bai, S. A., Walle, K., \& Walle, T. (1985). Influence of food on the intravenous and oral dose kinetics of propranolol in the dog. Journal of Pharmacokinetics and Biopharmaceutics, 13(3), 229-241. https://doi. org/10.1007/BF01065654

Banker, M. J., \& Clark, T. H. (2008). Plasma/serum protein binding determinations. Current Drug Metabolism, 9, 854-859.

Batzias, G. C., Delis, G. A., \& Koutsoviti-Papadopoulou, M. (2005a). Bioavailability and Pharmacokinetics Of Sulphadiazine, N4acetylsulphadiazine and trimethoprim following intravenous and intramuscular administration of a sulphadiazine/trimethoprim combination in sheep. Veterinary Research Communications, 29(8), 699-712. https://doi.org/10.1007/s11259-005-3868-6

Batzias, G. C., Delis, G. A., \& Koutsoviti-Papadopoulou, M. (2005b). Bioavailability and pharmacokinetics of sulphadiazine, n 4 - acetylsulphadiazine and trimethoprim following intravenous and intramuscular administration of a sulphadiazine / trimethoprim combination in sheep. Veterinary Research Communications, 29, 699-712. https:// doi.org/10.1007/s11259-005-3868-6

Bon, C., Toutain, P. L., Concordet, D., Gehring, R., Martin-Jimenez, T., Smith, J., ... Mochel, J. P. (2018). Mathematical modeling and simulation in animal health. Part III: Using nonlinear mixed-effects to characterize and quantify variability in drug pharmacokinetics. Journal of Veterinary Pharmacology and Therapeutics, 41(2), 171-183. https:// doi.org/10.1111/jvp.12473.

Bushby, S. R. M. (1973). Trimethoprim-sulfamethoxazole: In vitro microbiological aspects. The Journal of Infectious Diseases, 128(Supplement_3), S442-S462. https://doi.org/10.1093/infdi s/128.Supplement_3.S442.

Bushby, S. R. M. (1980). Sulfonamide and trimethoprim combinations. Journal of the American Veterinary Medical Association, 176(10), 1049-1053.

Bushby, S. R. M., \& Hitchings, G. H. (1968). Trimethoprim, a sulphonamide potentiator. British Journal of Pharmacology and Chemotherapy, 33(1), 72-90. https://doi.org/10.1111/j.1476-5381.1968.tb004 75.x.

Cheng, A. C., McBryde, E. S., Wuthiekanun, V., Chierakul, W., Amornchai, P., Day, N. P. J., ... Peacock, S. J. (2009). Dosing regimens of cotrimoxazole (trimethoprim-sulfamethoxazole) for melioidosis. Antimicrobial Agents and Chemotherapy, 53(10), 4193-4199. https:// doi.org/10.1128/AAC.01301-08.

CLSI (2019). Performance Standards for Antimicrobial Susceptibility Testing. CLSI supplement M100, 29th ed. Wayne, PA: CLSI.

Drenkard, E. (2003). Antimicrobial resistance of Pseudomonas aeruginosa biofilms. Microbes and Infection, 5(13), 1213-1219. https://doi. org/10.1016/j.micinf.2003.08.009.

Ekström, B., Forsgren, U., Örtengren, B., \& Bergan, T. (1979). Development of sulphonamide-trimethoprim combinations for urinary tract infections. Infection, 7(S4), S359-S366. https://doi.org/10.1007/BF01639014.

Elvin, A. T., Cole, A. F. D., Pieper, J. A., Rolbin, S. H., \& Lalka, D. (1981). Effect of food on lidocaine kinetics: Mechanism of food-related alteration in high intrinsic clearance drug elimination. Clinical Pharmacology \& Therapeutics, 30(4), 455-460. https://doi. org/10.1038/clpt.1981.188.

Greko, C., Bengtsson, B., Franklin, A., Jacobsson, S.-O., Wiese, B., \& Luthman, J. (2002). Efficacy of trimethoprim-sulfadoxine against Escherichia coli in a tissue cage model in calves. Journal of Veterinary Pharmacology and Therapeutics, 25(6), 413-423. https://doi. org/10.1046/j.1365-2885.2002.00431.x.

Gustafsson, A., Baverud, V., Franklin, A., Gunnarsson, A., Ogren, G., \& Ingvast-Larsson, C. (1999). Repeated administration of trimethoprim/sulfadiazine in the horse -pharmacokinetics, plasma protein binding and influence on the intestinal microflora. Journal of Veterinary Pharmacology and Therapeutics, 22(1), 20-26. https://doi. org/10.1046/j.1365-2885.1999.00183.x.

Høiby, N., Ciofu, O., \& Bjarnsholt, T. (2010). Pseudomonas aeruginosa biofilms in cystic fibrosis. Future Microbiology, 5(11), 1663-1674. https:// doi.org/10.2217/fmb.10.125.

Karlsson, M. O., \& Savic, R. M. (2007). Diagnosing model diagnostics. Clinical Pharmacology \& Therapeutics, 82(1), 17-20. https://doi. org/10.1038/sj.clpt.6100241.

Kielhofner, M. A. (1990). Trimethoprim- sulfamethoxazole: pharmacokinetics, clinical uses, and adverse reactions. Texas Heart Institute Journal, 17(2), 86-93.

Köhler, T., Kok, M., Michea-Hamzehpour, M., Plesiat, P., Gotoh, N., Nishino, T., Pechere, J. C. (1996). Multidrug efflux in intrinsic resistance to trimethoprim and sulfamethoxazole in Pseudomonas aeruginosa. Antimicrobial Agents and Chemotherapy, 40(10), 2288-2290. https://doi.org/10.1128/AAC.40.10.2288

Lees, P., Aliabadi, M. H. S., \& Toutain, P.-L. (2004). PK-PD modelling: an alternative to dose titration studies for antimicrobial drug dosage selection. Regulatory Affairs Journal, January, 175-180. 
Mengelers, M. J. B., Hougee, P. E., Janssen, L. H. M., \& Van Miert, A. S. J. P. A. M. (1997). Structure-activity relationships between antibacterial activities and physicochemical properties of sulfonamides. Journal of Veterinary Pharmacology and Therapeutics, 20(4), 276-283. https://doi.org/10.1046/j.1365-2885.1997.00063.x.

Mould, D. R., \& Upton, R. N. (2012). Basic concepts in population modeling, simulation, and model-based drug development. cpt: pharmacometrics \& systems. Pharmacology, 1(9), e6. https://doi.org/10.1038/ psp.2012.4.

Mouton, J. W., Brown, D., Apfalter, P., Cantón, R., Giske, C. G., Ivanova, M., ... Kahlmeter, G. (2012). The role of pharmacokinetics/pharmacodynamics in setting clinical MIC breakpoints: the EUCAST approach. Clinical Microbiology and Infection, 18(3), E37-E45. https:// doi.org/10.1111/j.1469-0691.2011.03752.x.

Mouton, J. W., Muller, A. E., Canton, R., Giske, C. G., Kahlmeter, G., \& Turnidge, J. (2018). MIC-based dose adjustment: facts and fables. Journal of Antimicrobial Chemotherapy, 73(3), 564-568. https://doi. org/10.1093/jac/dkx427.

Muller, A. E., Theuretzbacher, U., \& Mouton, J. W. (2015). Use of old antibiotics now and in the future from a pharmacokinetic/pharmacodynamic perspective. Clinical Microbiology and Infection, 21(10), 881-885. 0.1016/j.cmi.2015.06.007

Nielsen, P., \& Gyrd-Hansen, N. (1994). Oral bioavailability of sulphadiazine and trimethoprim in fed and fasted pigs. Research in Veterinary Science, 56(1), 48-52. https://doi.org/10.1016/0034-5288(94)90195-3.

Nikolaisen, N. K., Lassen, D. C. K., Chriél, M., Larsen, G., Jensen, V. F., \& Pedersen, K. (2017). Antimicrobial resistance among pathogenic bacteria from mink (Neovison vison) in Denmark. Acto Veterinaria Scandinavica, 59(1), 60. https://doi.org/10.1186/ s13028-017-0328-6.

Nimmo, W. S., \& Peacock, J. E. (1988). Effect of anaesthesia and surgery on pharmacokinetics and pharmacodynamics. British Medical Bulletin, 44(2), 286-301. https://doi.org/10.1093/oxfordjournals. bmb.a072252.

Pedersen, K., Hammer, A. S., Sørensen, C. M., \& Heuer, O. E. (2009). Usage of antimicrobials and occurrence of antimicrobial resistance among bacteria from mink. Veterinary Microbiology, 133(1-2), 115122. https://doi.org/10.1016/j.vetmic.2008.06.005

Sadaka, C., Kanellos, T., Guardabassi, L., Boucher, J., \& Watts, J. L. (2017). Evaluation of veterinary-specific interpretive criteria for susceptibility testing of Streptococcus equi subspecies with trimethoprim-sulfamethoxazole and trimethoprim-sulfadiazine. Journal of Clinical Microbiology, 55(1), 326-330. https://doi.org/10.1128/ JCM.01610-16.

Schwarz, S., L. M. Cavaco, J. Shen, \& F. M. Aarestrup (Eds.) (2018). Antimicrobial resistance in bacteria from livestock and companion animals (First). Washington DC: ASM Press.

Shoaf, S. E., Schwark, W. S., \& Guard, C. L. (1989). Pharmacokinetics of sulfadiazine/trimethoprim in neonatal male calves: effect of age and penetration into cerebrospinal fluid. American Journal of Veterinary Research, 50(3), 396-403. https://europepmc.org/abstract/ med/2930028

Sigel, C. W., Ling, G. V., Bushby, S. R., Woolley, J. L. Jr, DeAngelis, D., \& Eure, S. (1981). Pharmacokinetics of trimethoprim and sulfadiazine in the dog: urine concentrations after oral administration. American Journal of Veterinary Research, 42(6), 996-1001.

Toutain, P. L., Bousquet-Mélou, A., Damborg, P., Ferran, A. A., Mevius, D., Pelligand, L., ... Lees, P. (2017). En route towards european clinical breakpoints for veterinary antimicrobial susceptibility testing: a position paper explaining the VetCAST approach. Frontiers in Microbiology, 8, 2344. https://doi.org/10.3389/fmicb.2017.02344.

Toutain, P.-L., Del Castillo, J. R. E., \& Bousquet-Mélou, A. (2002). The pharmacokinetic-pharmacodynamic approach to a rational dosage regimen for antibiotics. Research in Veterinary Science, 73(2), 105114. https://doi.org/10.1016/S0034-5288(02)00039-5.

Turnidge, J., Kahlmeter, G., \& Kronvall, G. (2006). Statistical characterization of bacterial wild-type MIC value distributions and the determination of epidemiological cut-off values. Clinical Microbiology and Infection, 12(5), 418-425. https://doi. org/10.1111/J.1469-0691.2006.01377.X

Van Duijkeren, E., Ensink, J. M., \& Meijer, L. A. (2002). Distribution of orally administered trimethoprim and sulfadiazine into noninfected subcutaneous tissue chambers in adult ponies. Journal of Veterinary Pharmacology and Therapeutics, 25(4), 273-277. https:// doi.org/10.1046/j.1365-2885.2002.00418.x.

Van Duijkeren, E., Vult, A. G., Oldruitenborgh-oosterbaan, M. M. S. V., Mevius, D. J., Kessels, B. G. F., Breukink, H. J., \& Mierts, A. S. J. P. A. M. V. (1994). A comparative study of the pharmacokinetics of intravenous and oral trimethoprim/sulfadiazine formulations in the horse. Journal of Veterinary Pharmacology and Therapeutics, 17(6), 440-446. https://doi.org/10.1111/j.1365-2885.1994.tb00275.x.

Van Miert, A. S. J. P. A. M. (1994). The sulfonamide-diaminopyrimidine story. Journal of Veterinary Pharmacology and Therapeutics, 17(4), 309-316. https://doi.org/10.1111/j.1365-2885.1994.tb00251.x.

Villa, R. E., Prandini, E., Caloni, F., \& Carli, S. (1997). Serum protein binding of some sulfonamides, quinolones and fluoroquinolones in farm and domestic animals. Journal of Veterinary Pharmacology and Therapeutics, 20(suppl.1(60)), 34-35.

Yamaoka, K., Nakagawa, T., \& Uno, T. (1978). Application of Akaike's information criterion (AIC) in the evaluation of linear pharmacokinetic equations. Journal of Pharmacokinetics and Biopharmaceutics, 6(2), 165-175. https://doi.org/10.1007/BF01117450.

\section{SUPPORTING INFORMATION}

Additional supporting information may be found online in the Supporting Information section.

How to cite this article: Ronaghinia AA, Nikolaisen NK, Hansen SG, et al. Validating an empiric sulfadiazine-trimethoprim dosage regimen for treatment of Escherichia coli and Staphylococcus delphini infections in mink (Neovison vison). J vet Pharmacol Therap. 2021;44:93-106. https://doi.org/10.1111/ jvp.12894 